have either a living will or a durable power of attorney) and are frequently mistrusted as gimmicks to reduce the cost of health care.

The essays are clearly written, free from philosophical jargon, and the author frankly admits that they are not based upon a rockbed moral theory or meta-ethical foundation. There are obvious merits in this non-foundational and pragmatic approach: the author is free from the dogmatic belief that what can solve a problem in one area must also be capable of solving problems in other areas. For Caplan there is no Holy Grail for medical ethics. Nevertheless, he is not without a method: the aim of the ethicist, he says, is to identify and determine the nature of the problem, to pinpoint its source, and to see whether it is possible and desirable to do something about it.

Aside from the many practical issues addressed here Caplan makes an important contribution to the debate about whether applied ethics can play an effective role in health care. There is a growing backlash against philosophical experts in medical ethics and Caplan is concerned to pinpoint the source of resentment among health care professionals. In many respects, he observes, the moral theorist plays a diversionary role in ethical decision-making; it is, for example, far easier to employ moral philosophers to theorize on the ethics of allocating scarce resources than to ask health-workers and patients to accept the fact that society is unwilling to fund resources for those who are in need. One of the main problems with applied ethics, says Caplan, is the commitment to 'the engineering model', which presumes that a body of knowledge about ethics can be employed in medical settings by the deduction of conclusions from theories, analysing the process of deduction, and then applying ethical theories to medicine in an impartial, disinterested, and value-free manner. This methodology once dominated the philosophy of the natural and social sciences and it is puzzling why it has taken hold in applied ethics when it has been so forcibly discredited in the philosophy of science. Why applied ethics has become the final rest home for the nomological-deductive model of explanation is a project worthy of serious study.

This book is strongly recommended as a useful and pragmatic contribution to the philosophy of health care, which calls for a reassessment of the relationship between philosophy and medical practice and addresses numerous ethical problems which have recently come to the forefront of public concern.

DAVID LAMB Department of Bioethics, University of Birmingham

\section{New horizons in the philosophy of science}

Edited by David Lamb, London,
Avebury, 1992, 191 pages, $£ 30.00$

This is a collection of articles committed to challenging current orthodoxies in the philosophy of science. In the first, Richard F Kitchener maintains that mainstream philosophy of science is intrinsically 'positivist', a dirty word in anyone's mouth these days. He makes a number of fairly astute criticisms of the narrow focus of much of the work in this field, and urges that philosophers should draw on metaphysics, on ethics, on sociology, and a greater knowledge of science to make a more radical and significant contribution. As David Lamb's introduction stresses, the articles in this book are intended to be examples of just such a radical and ambitious approach.

Given this build-up, Lamb's own contribution is unexpectedly traditional in approach. In 'Death: the final frontier', he argues cogently that we ought to regard irreversible damage to the brainstem as the sole criterion of death. This has ethical consequences, such as how we regard certain terminations of treatment. If a patient's brainstem is dead, and the ventilator is subsequently switched off, then it is wrong to say that 'life support has been disconnected'. Doctors have just chosen not to continue treating a dead body. This is a good example of how philosophy can contribute to the way we think about medical practice.

E K Ledermann uses case studies to argue that a 'mechanistic-scientific' approach to treatment is inadequate. A 'holistic' approach, which acknowledges and influences the personal feelings and circumstances of the patient, is to be preferred to treatment that views the patient as one would a damaged machine. It is difficult to disagree with this claim; it is surely right to suggest that there are psychological factors involved in both the causes and the best treatments of many ailments. What is hard to believe is that many doctors disagree. We are told that 'Patients seek treatment from $\stackrel{\varnothing}{2}$ doctors who follow either mechan- I istic-scientific or holistic principles'. Do doctors really fall so neatly into one camp or the other?

Lucy Frith's article, 'Sociobiology, ethics and human nature', might give us some reason to think that a mechanistic view, not just of illness, but of human affairs in general requires examination. Her excellent article reviews the arguments for socio- $\infty$ biology, the view that all human $\overrightarrow{0}$ behaviour is genetically encoded. She $\vec{A}$ shows just how far some philosophers $\vec{\omega}$ are willing to take this view, and provides a sustained critique both of this strong view and of a weaker iv version which allows some environmental influences.

In 'A sociological perspective on disease', Kevin White attacks 'empiricist' and 'normative' analyses of disease. He points out that what we classify as a disease is greatly affected by our social attitudes. Someone can cease to be 'diseased' simply through a change in attitudes; for example, $\vec{\bullet}$ certain sexual predilections were once 6 thought of as diseases. This is a goog point to make, even if we are not entirely convinced that there is a con flict between 'empiricist' and 'soci $\sigma^{2}$ logical' analyses. If a person has cancer then there is a fact of the matter as to what is happening in his or her body (empirical), and we choose to call this a disease (sociological). Nonetheless, White provides a good discussion of the sociological issues.

The rest of the book is devoted to $\bar{\nabla}$ general issues in the philosophy of $\overline{0}$ science, such as the 'evolutionary par- 3 . adigm' and the nature of scientific 8 knowledge. This is a useful reference $\exists$ text; most of the ten articles provide general reviews of available literature on the different questions they tackle.

MICHAEL GAYLARD Darwin College, Cambridge

\section{Morality, mortality vol 1: death and whom to save from it}

\author{
F M Kamm, Oxford, Oxford \\ University Press, 1993, viii +344 \\ pages, $£ 35$ (cloth)
}

Imagine yourself in a row boat, $\bar{Q}$ equidistant from two large rock outcrops. On the first rock, there is only 